\title{
3-Year follow-up of a single magnetically controlled growing rod with contralateral gliding system and apical control for early onset scoliosis
}

\author{
Sebastiaan P. J. Wijdicks ${ }^{1} \cdot$ Simon Toftgaard Skov ${ }^{2,3} \cdot$ Haisheng Li ${ }^{2} \cdot$ René M. Castelein ${ }^{1} \cdot$ Moyo C. Kruyt ${ }^{1}$. \\ Cody Bünger ${ }^{2,3}$
}

Received: 14 February 2020 / Accepted: 25 February 2020 / Published online: 30 March 2020

(C) The Author(s) 2020

\begin{abstract}
Study design Two-center retrospective cohort study.

Objective The aim of this study is to investigate the clinical effectiveness and safety of the MCGR hybrid in terms of spinal growth, 3D correction, balance, and complications.

Summary of background data The magnetic-controlled growing-rod (MCGR) growth instrumentation method has gained popularity for early onset scoliosis (EOS) treatment in the past years due to the non-invasiveness of the subsequent interval elongation procedures. To improve 3D correction and reduce the costs, we combined a single concave MCGR with a sliding rod on the convex side to control the apex.

Methods A retrospective cohort study of 18 EOS children with an average 3-year follow-up (range 2.0-3.7) from two European spine centers treated with the single MCGR hybrid concept; 14 primary and 4 conversion cases. The primary and conversion cases were both evaluated preoperatively, postoperatively, 1 year, 2 years, and last follow-up.

Results Mean age was 9.9 ( $\mathrm{SD} \pm 2.9$ years). The average frontal Cobb angle was reduced from mean $65^{\circ}$ to $30^{\circ}$ postoperatively, and had increased to $37^{\circ}$ at latest follow-up. Rotation of the apical vertebra improved from mean $27^{\circ}$ to $20^{\circ}$ postoperatively which was partially lost to $23^{\circ}$. Kyphosis and lordosis both increased by an average of $5^{\circ}$ during the time of follow-up. Spinal balance was improved. The post-implantation T1-S1 spine growth rate averaged $10 \mathrm{~mm} / \mathrm{year}$ at last follow-up. There were 13 implant-related complications in 6 out of 18 patients. No screw pull-outs and nor surgical site infections were registered.
\end{abstract}

Conclusions This is the first medium-term results of a single MCGR hybrid construct. Maintenance of correction and growth are reasonable, and the complication rate is relatively low as compared to bilateral MCGR application.

Level of evidence III.

Keywords MCGR - Early onset scoliosis · Growing rod instrumentation · Growth friendly system · Minimal invasive surgical procedure $\cdot$ Apical control

Sebastiaan P. J. Wijdicks and Simon Toftgaard Skov are co-first authors, and have contributed equally to this work.

Disclaimers Local ethical committee approval was granted for this study (ref. 18/638, ref. 126/2014).

Sebastiaan P. J. Wijdicks

s.p.j.wijdicks@umcutrecht.nl

1 Department of Orthopaedic Surgery, University Medical Center Utrecht, Heidelberglaan 100, 3584CX Utrecht, The Netherlands

2 Department of Orthopaedic Surgery, Aarhus University Hospital, Palle Juul-Jensens Boulevard 99, 8200 Aarhus, Denmark
Orthopaedic Research Laboratory, Aarhus University Hospital, Palle Juul-Jensens Boulevard 99, 8200 Aarhus, Denmark 


\section{Introduction}

Progressive early onset scoliosis (EOS) can become a hazard to pulmonary development and function [1,2]. Different "growth-friendly systems" and implants have been developed to control the scoliosis deformity and allow for continuous spinal growth and thereby support the truncal development. Traditional growing rods were widely used in severe EOS throughout the last decades, but required repeated surgical lengthening procedures under general anesthesia coupled with relatively high infection rates [3,4]. Magnetically controlled growing rods (MCGRs) (Magec, NuVasive, San Diego, CA, USA) were introduced about 10 years ago with the first publication in 2012 [5]. It is recommended for dual or single rod application according to the needs of the individual patient. MCGRs allow for non-invasive distraction of the rod construct by electromagnetic stimulation without sedation.

We combined a single MCGR to drive the concave lengthening with a contralateral passive sliding-rod construct on the convexity to improve the 3D deformity correction. An anchor site was added at the apex to increase the stability and aid for axial deformity correction [6]. Dual rods instead of single rods have been advised in the traditional growing-rod treatment because of better correction, spinal growth, and lower implant-related complications [7, 8]. After MCGR became available, the dual MCGR rod construct has become a popular treatment in many centers despite the high initial implant cost [5]. The advantages of a dual MCGR over a single MCGR construct has been advocated by a recent systematic review which found fewer implant-related failures including a lower frequency of rod breakage [7]. The bilateral support of our proposed hybrid construct follows a dual-rod principle with added apical support and could reduce complications including rod breakage. Finally, costs using the MCGR can be reduced by obviating the need for surgical distractions and only requiring outpatient clinic visits [9]. Moreover, reducing the initial device costs of a dual MCGR (20.000 USD) to a single MCGR (10.000 USD) could further reduce overall costs [9-11]. Substituting the second MCGR with an inexpensive gliding construct anchored apically with one or two pedicle screws could further reduce overall costs. Therefore, utilizing a single MCGR in this hybrid concept may improve 3D correction and spinal balance at a reduced cost.

The aim of this study was to investigate both the 3D correction, the spinal growth and the complication rate of our new hybrid growing-rod-sliding-rod concept. We report the combined results from two European scoliosis centers: $\mathrm{U}$ and A.

\section{Materials and methods}

\section{Study design}

A retrospective cohort study of all consecutive EOS patients irrespective etiology, treated with the hybrid MCGR and apical control from September 2014 to June 2016 at U and A spine centers was evaluated. The inclusion criteria for this study and MCGR hybrid surgery were: skeletal immaturity, progressive scoliosis, and a major curve of more than $45^{\circ}$. A sample size of 18 was attained by selecting all patients who received the hybrid MCGR at any time at one of the two institutions and had a minimum of 2-year follow-up. We report preoperative, postoperative, 6 months, 1 year, 2 years, and last follow-up results including spinal growth, 3D correction, complications, and re-operations. Data collection and data storage were approved in accordance with the national guidelines for research ethics and data protection. This study followed the STROBE guideline for reporting observational studies [12].

\section{Surgical techniques}

The patients were placed in balanced prone position without traction. Standard infection prevention precautions were taken including perioperative intravenous antibiotics. Topical wound administration (e.g., Vancomycin) was not applied in any of the patients. A posterior midline approach was used at the three strategic anchor sites for pedicle screw placement, identified by fluoroscopy. Commercially available pediatric spine implants for 4.5 - or $5.5-\mathrm{mm}$ rods including MCGR were used. On the concave side, a contoured MCGR was tunneled subfascially and mounted at the proximal and distal anchor sites. On the convex side, a unilateral pedicle screw anchor site was added at the apex and used to mount the pre-assembled contoured passive sliding-rod construct, bridging the intermediate unexposed segments of the spine. The apex of the spine was identified intra-operatively and approached with a separate incision. The rods were contoured before insertion to accommodate proximal kyphosis and distal lordosis, to facilitate deformity correction, and to avoid proximal and distal junctional failures. Obviously, the actuator of the MCGR remains problematic also in this hybrid strategy. However, since the MCGR is positioned in the concavity, there is more margin for positioning without prominence as this side is typically deeper. On the more superficial convex side, the sliding rod can be contoured in any shape which is an advantage.

The passive sliding construct on the convex side differed between our two centers. In U, the $5.5 \mathrm{~mm} \mathrm{~K} 2 \mathrm{M}$ Mesa ${ }^{\circledR}$ and Magec $®$ systems were used. One long apical anchored rod was allowed to slide through proximal and distal parallel 


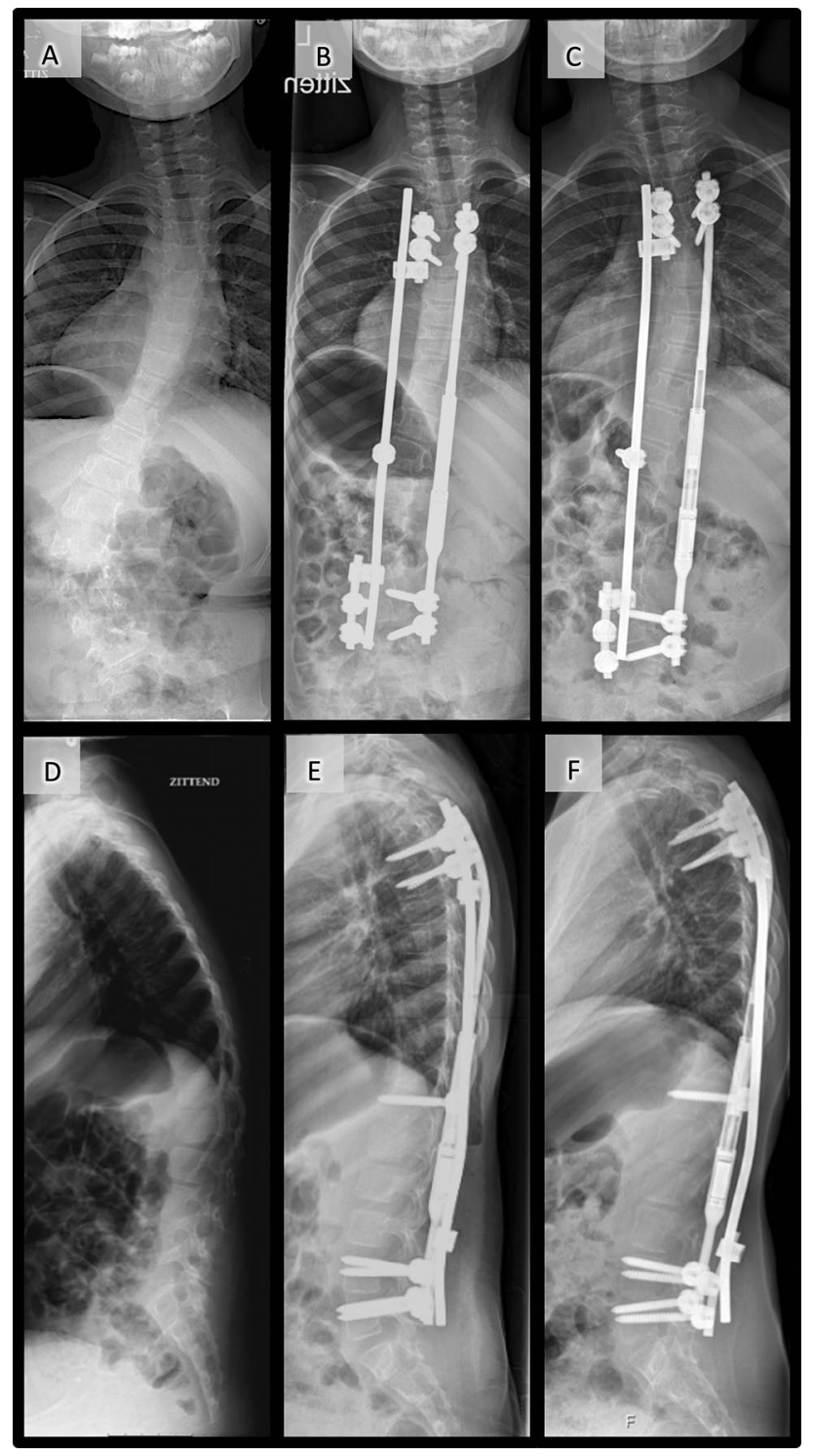

Fig. 1 Combined single magnetic rod and parallel block sliding rod system in a 7-year-old girl with spinal muscular atrophy type 2 : a frontal radiographs made preoperatively, $\mathbf{b}$ postoperative, and $\mathbf{c}$ at the time of final follow-up, and $\mathbf{d}$ sagittal radiographs made preoperatively, e postoperative, and $\mathbf{f}$ at the time of last follow-up

connectors. The parallel connectors had an oversize hole at the sliding-rod connection which was left open without set-screw (5.5 mm-diameter hole for a $4.5 \mathrm{~mm}$ rod) (Figs. 1 and 2). In $A$, the $X i a{ }^{\circledR}$ and $\mathrm{K} 2 \mathrm{M}$ Mesa ${ }^{\circledR} 4.5$ or $5.5 \mathrm{CD}$ Legacy ${ }^{\circledR}$ system and Magec 4.5 or 5.5 rods were used. The CB system was used for the convex side; three $4.5 \mathrm{~mm}$ rods assembled with two longitudinal connectors as growth tubes; each unlocked at one end to enable passive sliding between the three anchoring sites (Fig. 3).

MCGR distraction by external magnetic stimulation was conducted on an out-patient basis at 2.5-3-month intervals based on the manufacturer instructions [13]. Biplanar

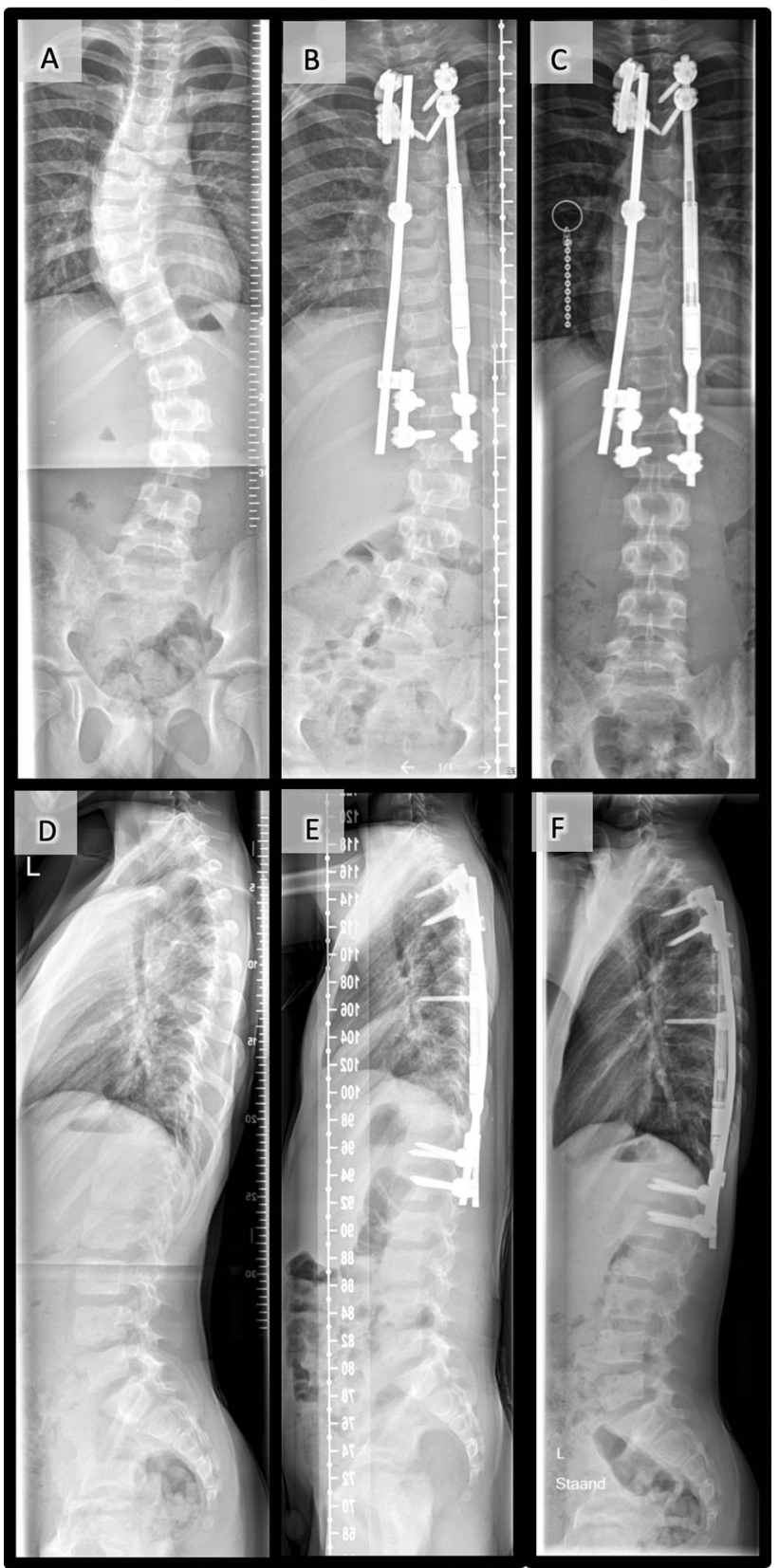

Fig. 2 Combined single magnetic rod and parallel block sliding rod system in an 8-year-old girl with idiopathic scoliosis: frontal radiographs made a preoperative, $\mathbf{b}$ postoperative, and $\mathbf{c}$ at the time of final follow-up. Sagittal radiographs made $\mathbf{d}$ preoperative, e postoperative, and $\mathbf{f}$ at the time of last follow-up

scoliosis radiographs were taken postoperatively and at 6-month intervals to balance between radiation exposure and adequate follow-up of the MCGR. Failure to distract was defined as a combination of multiple instances of slippage of the MCGR's internal mechanism (resulting in an audible clunking sound and failure of the internal magnet to distract the MCGR) and a lack of any MCGR distraction on consecutive radiographs. 


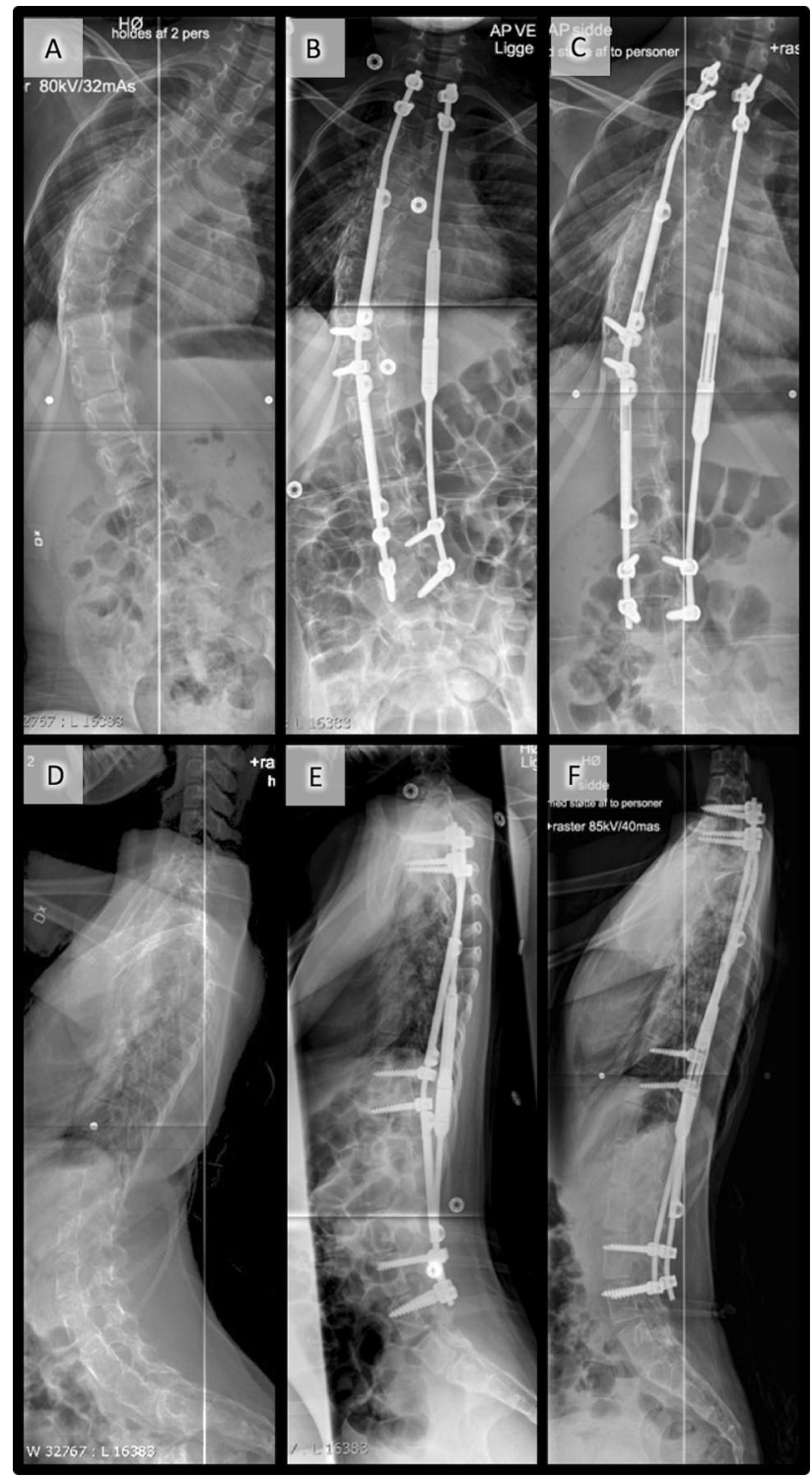

Fig. 3 Combined single magnetic rod and CB system in an 11-yearold girl with cerebral palsy: a frontal radiographs made preoperatively, $\mathbf{b}$ postoperative, and $\mathbf{c}$ at the time of final follow-up, and $\mathbf{d}$ sagittal radiographs made preoperatively, e postoperative, and $\mathbf{f}$ at the time of last follow-up

\section{Data collection}

Electronic patient files were reviewed for complications, reoperations, and distraction failures of the MCGR. Digital biplanar scoliosis radiographs were evaluated using Surgimap 2.2.14 spine measurement software (Nemaris Inc, New York, NY, USA). An investigator from each center performed the measurements. To reduce potential bias, the numbers were cross-audited and eventual discrepancies were solved with consensus. Scoliosis Cobb angle as well as the kyphosis (T4-T12) and lordosis (L1-L5) angles were measured. The rotation of the apical vertebra was measured
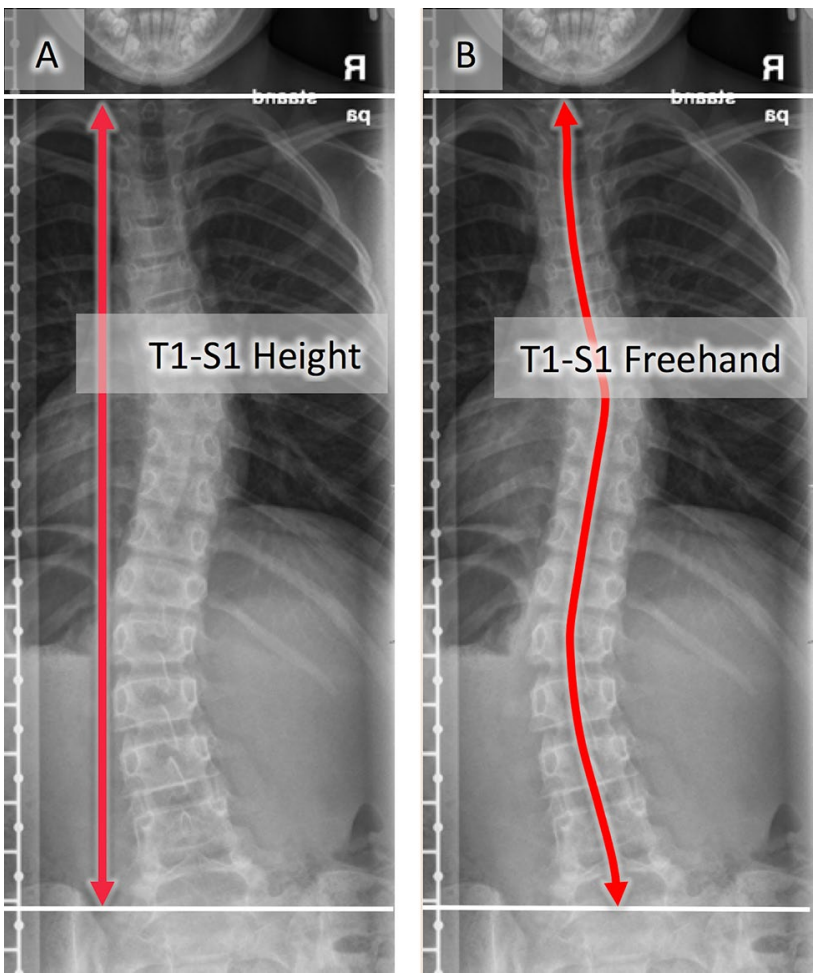

Fig. 4 T1-S1 spinal length measurements: T1-S1 height measurement example (Fig. 1a) and T1-S1 freehand example (Fig. 1b)

according to the Nash-Moe method, because neither one of our centers have ultra-low-dose 3D-imaging (e.g., EOS3D) available, and CT imaging is only applied on clinical indication to minimize the radiation exposure [14]. MCGR actuator diameter (narrow part $9.02 \mathrm{~mm}$, wide part $10.50 \mathrm{~mm}$ ) was applied to calibrate the radiographs for height measurements. T1-T12 height, T1-S1 height, and instrumented height were measured as the perpendicular distance between horizontal lines through the midpoints of the chosen vertebral endplates on coronal radiographs (Fig. 4a). The T1-S1 freehand measures represent a spinal length with a line drawn through the exact midpoint of the upper and lower endplates of every vertebra resulting in a line following the contour of the spine to achieve a more precise spinal length measurement. The Surgimap Free Rod tool was used for this measure by trailing the center points of the vertebral body endplates (Fig. 4b). The distraction length was measured on the MCGR. Growth rates were calculated based on the measurements from the first postoperative radiographs to the time point of the respective follow-ups. Furthermore, apical translation, coronal balance, and sagittal balance (in ambulatory patients) were measured to assess whether the deformity correction affected the global balance of the spine. 
Table 1 Patient demographics

\begin{tabular}{llll}
\hline & All $(n=18)$ & $\mathrm{U}(n=9)$ & $\mathrm{A}(n=9)$ \\
\hline No. of patients (male:female) & $4: 14$ & $3: 6$ & $1: 8$ \\
MCGR case (primary:conversion) & $14: 4$ & $8: 1$ & $6: 3$ \\
Etiology (Neuromuscular:Idiopathic:Syndromic) & $9: 6: 3$ & $4: 4: 1$ & $5: 2: 2$ \\
Age at the time of MCGR surgery (year) & $9.9(6.4-18.1)$ & $8.0(6.4-9.3)$ & $11.7(6.9-18.1)^{\mathrm{a}}$ \\
Surgery time (min) & $194(96-278)$ & $200(135-278)$ & $187(96-260)$ \\
Days of admission (days) & $5.4(1-12)$ & $6.4(3-12)$ & $4.3(1-7)$ \\
Instrumented levels (no. of levels) & $14(11-16)$ & $13(11-16)$ & $14(12-16)$ \\
Postoperative FU from MCGR surgery (mos) & $37(26-47)$ & $38(29-47)$ & $35(26-47)$ \\
\hline
\end{tabular}

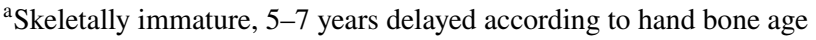

\section{Statistics}

Descriptive statistics and statistical analysis were performed with IBM SPSS Statistics 24.0 (IBM Corp. Armonk, New York, NY, USA) with a level of significance of $p<0.05$. Postoperative and last follow-up outcomes were analyzed with paired $t$ tests. Wilcoxon signed-rank test was used for data appearing non-normally distributed.

\section{Results}

\section{Patient demographics}

A total of 18 patients were included, followed up, and analyzed; 9 patients from each center, including 14 primary cases, and 4 conversion cases from traditional growing rods (Table 1). Of the 14 primary cases: 10 patients failed initial brace treatment, and 4 had curves not suited for brace treatment. All the patients were skeletally immature, mean age 9.9 \pm 2.9 years (range 6-18) with the oldest patient having a bone age of 11 years. All had a progressive scoliosis and an average Cobb angle of $65^{\circ} \pm 12^{\circ}$ (range 46-86). The Cobb angle reduction of the primary cases was $57 \%$ and the Cobb angle for the conversion cases was 7\%, compared to the initial curve. The conversion surgery itself yielded little extra correction, because the spines were stiff or had partial support by the previous system applied. The etiology was $50 \%$ neuromuscular $(n=9), 33 \%$ idiopathic $(n=6)$, and $17 \%$ syndromic $(n=3)$. Mean overall surgery time for MCGR implantation procedure was $193 \mathrm{~min}$ (range 96-278) and their average hospital admission time was 5.4 days (range $1-12$ ). The average follow-up time was 3 years (range 2-3.7).

\section{Radiographic outcomes}

The Cobb angle of the primary cases changed from mean $65^{\circ} \pm 13^{\circ}$ preoperatively to $28^{\circ} \pm 12^{\circ}$ postoperatively (55\% reduction). The mean frontal Cobb angle of the conversion cases was $64^{\circ} \pm 11^{\circ}$ at fist surgery and $38^{\circ} \pm 9^{\circ}$ at conversion. This curve was reduced considerably less as expected to $35^{\circ} \pm 6^{\circ}$ (Table 2). For all cases (primary and conversions) reduction from initial until after conversion was $59^{\circ} \pm 17^{\circ}$ to $30^{\circ} \pm 11^{\circ}$ (Table 3). This angle slightly increased to $37^{\circ} \pm 12^{\circ}$ at latest follow-up, $p<0.001$ (95\% CI 3.3-10.3) (Fig. 5). Individual demographics for every patient are visible in Table 2. Rotation of the apical vertebra improved from mean $27^{\circ} \pm 8^{\circ}$ to $20^{\circ} \pm 9^{\circ}$ postoperatively, but was partially lost to $23^{\circ} \pm 9^{\circ}$ during follow-up, $p=0.261$ (95\% CI $-2.5-8.6)$. Kyphosis and lordosis both increased by an average of $5^{\circ}$ during follow-up (Table 3). T1-S1 height increased from average $337 \pm 31 \mathrm{~mm}$ postoperatively to $361 \pm 39 \mathrm{~mm}$ at last follow-up, $p<0.001$ (95\% CI 13.5-33.3) (Fig. 6). Spinal T1-S1 growth rate averaged $10 \mathrm{~mm} /$ year over 3 years until last follow-up (Table 4). There was no difference in growth rate between conversion and primary cases (Table 2).

Table 2 Primary vs. conversion: angle and spinal growth rates (mean $\pm \mathrm{SD}$; range)

\begin{tabular}{lllllll}
\hline & $\begin{array}{l}\text { Pre-op major } \\
\text { curve }(n=18) \\
(\mathrm{deg})\end{array}$ & $\begin{array}{l}\text { Post-op major } \\
\text { curve }(n=18) \\
(\mathrm{deg})\end{array}$ & $\begin{array}{l}\text { Last FU major } \\
\text { curve }(n=18) \\
(\mathrm{deg})\end{array}$ & $\begin{array}{l}\text { T1-T12 length gain } \\
\text { rate post-op to last FU } \\
(n=18)(\mathrm{mm} / \text { year })\end{array}$ & $\begin{array}{l}\text { T1-S1 length gain } \\
\text { rate post-op to last FU } \\
(n=18)(\mathrm{mm} / \text { year })\end{array}$ & $\begin{array}{l}\text { Instrumented gain } \\
\text { rate post-op to last FU } \\
(n=18)(\mathrm{mm} / \text { year })\end{array}$ \\
\hline Primary & $65 \pm 13$ & $28 \pm 12$ & $38 \pm 14$ & $6.1 \pm 5.6$ & $10.2 \pm 9.2$ & $9.1 \pm 7.2$ \\
& $(46-86)$ & $(8-49)$ & $(19-67)$ & $(-3.6-19.3)$ & $\begin{array}{l}(-0.3-30.3) \\
(-0.4-21.4)\end{array}$ \\
Conversion & $38 \pm 9$ & $35 \pm 6$ & $33 \pm 5$ & $8.8 \pm 4.4$ & $8.9 \pm 5.4$ \\
& $(26-47)$ & $(29-43)$ & $(28-39)$ & $(5.6-15.3)$ & $(4.7-19.5)$ & $(.04-16.2)$ \\
\hline
\end{tabular}

Pre-op radiograph before MCGR implantation surgery, Post-op radiograph before discharge from hospital, FU follow-up 
Table 3 3D correction: angle, rotation, or distance (mean \pm SD; range)

\section{Pre-op $(n=18) \quad$ Post-op $(n=18) \quad$ Last FU $(n=18) \quad$ Change pre-op to Change post-op to Change post-} post-op $(n=18) \quad$ 2-year FU $(n=18) \quad$ op to last FU $(n=18)$

\begin{tabular}{|c|c|c|c|c|c|c|}
\hline Frontal Cobb (deg) & $\begin{array}{l}65 \pm 12 * \\
(46-86)\end{array}$ & $\begin{array}{l}30 \pm 11 \\
(8-49)\end{array}$ & $\begin{array}{l}37 \pm 12 \\
(19-67)\end{array}$ & $\begin{array}{l}-35 \pm 12 \\
(-16-65)\end{array}$ & $\begin{array}{l}6 \pm 7 \\
(-4-18)\end{array}$ & $\begin{array}{l}7 \pm 7 \\
(-4-18)\end{array}$ \\
\hline Rotation Nash-Moe (deg) & $\begin{array}{l}27 \pm 8 \\
(13-42)\end{array}$ & $\begin{array}{l}20 \pm 9 \\
(5-36)\end{array}$ & $\begin{array}{l}23 \pm 9 \\
(6-41)\end{array}$ & $\begin{array}{l}-7 \pm 9 \\
(-26-11)\end{array}$ & $\begin{array}{l}1 \pm 10 \\
(-15-22)\end{array}$ & $\begin{array}{l}3 \pm 11 \\
(-15-26)\end{array}$ \\
\hline Apical translation $(\mathrm{cm})$ & $\begin{array}{l}5.5 \pm 2.7 \\
(1.5-11.1)\end{array}$ & $\begin{array}{l}2.7 \pm 1.6 \\
(0.1-5.5)\end{array}$ & $\begin{array}{l}2.8 \pm 1.6 \\
(0.3-6.0)\end{array}$ & $\begin{array}{l}-2.8 \pm 2.2 \\
(-8.1-0.2)\end{array}$ & $\begin{array}{l}0.1 \pm 1.6 \\
(-2.5-3.9)\end{array}$ & $\begin{array}{l}0.1 \pm 1.8 \\
(-2.7-3.9)\end{array}$ \\
\hline Coronal balance $(\mathrm{cm})$ & $\begin{array}{l}2.2 \pm 1.4 \\
(0.3-5.5)\end{array}$ & $\begin{array}{l}1.9 \pm 1.8 \\
(0.1-6.5)\end{array}$ & $\begin{array}{l}1.5 \pm 1.6 \\
(0.1-5.6)\end{array}$ & $\begin{array}{l}-0.2 \pm 2.1 \\
(-3.5-4.2)\end{array}$ & $\begin{array}{l}-0.3 \pm 2.7 \\
(-4.6-6.3)\end{array}$ & $\begin{array}{l}-0.4 \pm 2.3 \\
(-4.0-6.4)\end{array}$ \\
\hline Kyphosis T4-T12 (deg) & $\begin{array}{l}27 \pm 19 \\
(2-67)\end{array}$ & $\begin{array}{l}20 \pm 12 \\
(4-53)\end{array}$ & $\begin{array}{l}24 \pm 17 \\
(0-62)\end{array}$ & $\begin{array}{l}-7 \pm 15 \\
(-47-13)\end{array}$ & $\begin{array}{l}3 \pm 11 \\
(-21-29)\end{array}$ & $\begin{array}{l}5 \pm 11 \\
(-21-29)\end{array}$ \\
\hline Lordosis L1-L5 (deg) & $\begin{array}{l}37 \pm 17 \\
(6-65)\end{array}$ & $\begin{array}{l}34 \pm 13 \\
(17-57)\end{array}$ & $\begin{array}{l}40 \pm 13 \\
(13-64)\end{array}$ & $\begin{array}{l}-3 \pm 12 \\
(-26-15)\end{array}$ & $\begin{array}{l}5 \pm 9 \\
(-8-26)\end{array}$ & $\begin{array}{l}5 \pm 10 \\
(-8-31)\end{array}$ \\
\hline Sagittal balance $^{\dagger}(\mathrm{cm})$ & $\begin{array}{l}3.7 \pm 2.0 \\
(0.0-6.3)\end{array}$ & $\begin{array}{l}4.0 \pm 2.6 \\
(0.0-9.6)\end{array}$ & $\begin{array}{l}3.1 \pm 2.4 \\
(0.2-7.9)\end{array}$ & $\begin{array}{l}-0.4 \pm 2.4 \\
(-2.8-3.9)\end{array}$ & $\begin{array}{l}-1.5 \pm 3.4 \\
(-7.3-5.6)\end{array}$ & $\begin{array}{l}-0.9 \pm 3.9 \\
(-8.5-5.6)\end{array}$ \\
\hline
\end{tabular}

Pre-op radiograph before MCGR implantation surgery, Post-op radiograph before discharge from hospital, $F U$ follow-up

$*$ Pre-primary values applied for all conversion cases $\left(59^{\circ} \pm 17^{\circ}\right.$ if values before magnetic rod implantation)

${ }^{\dagger}$ Only in ambulatory patients

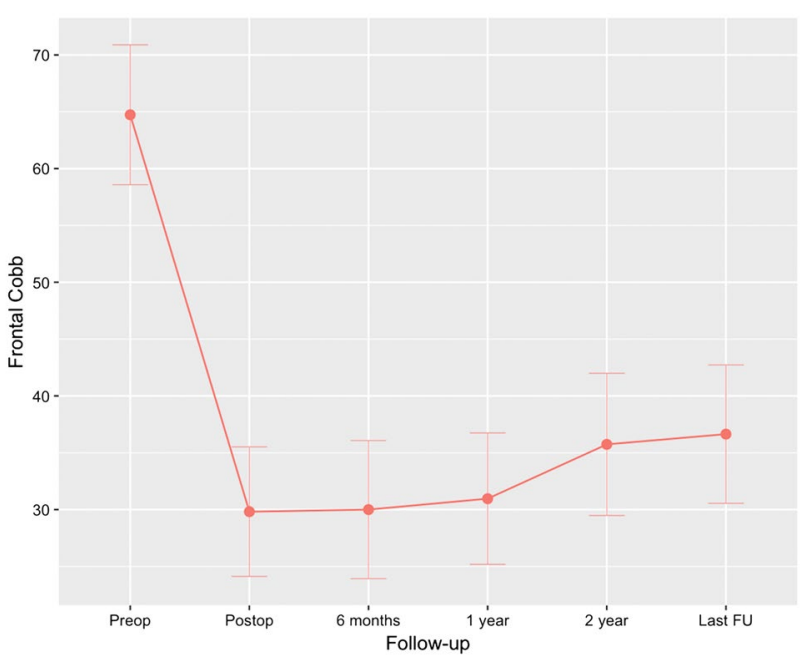

Fig. 5 Frontal Cobb Angle: error bars represent the 95\% confidence intervals

None of the patients reached the maximum distraction point of the rod during follow-up.

The average apical translation (deviation from the midline) was $5.5 \pm 2.7 \mathrm{~cm}$ and improved to $2.7 \pm 1.6 \mathrm{~cm}$ and remained stable at $2.8 \pm 1.6 \mathrm{~cm}$ at last follow-up. Coronal balance (deviation of the $\mathrm{C} 7$ plumb line from the sacral midline) changed $2.2 \pm 1.4 \mathrm{~cm}$ to $1.9 \pm 1.8 \mathrm{~cm}$ postoperatively to $1.5 \pm 1.6 \mathrm{~cm}$ at last follow-up. The sagittal balance in ambulatory patients $(n=12)$ changed from $3.7 \pm 2.0 \mathrm{~cm}$ to $4.0 \pm 2.6 \mathrm{~cm}$ postoperatively and to $3.1 \pm 2.4 \mathrm{~cm}$ at last follow-up (Table 5).

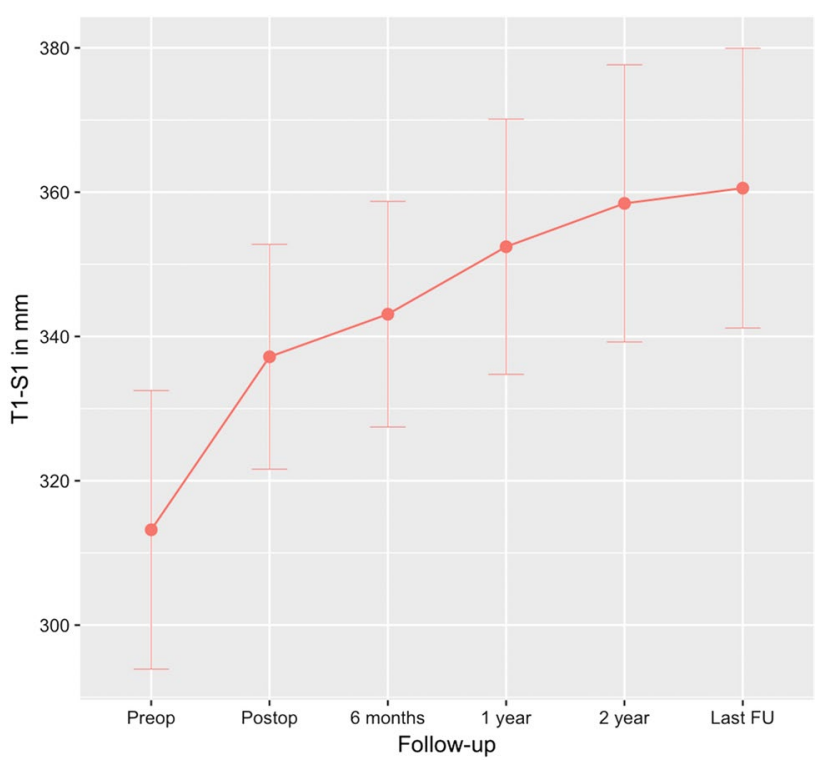

Fig. 6 T1-S1 height: error bars represent the 95\% confidence intervals

\section{Complications}

No intraoperative or perioperative procedure-related adverse events were registered. Five unplanned surgeries occurred in 4 out of 18 patients (22\%). There was a total of 9 implant-related complications in 6 out of 18 patients (33\%) (Table 5). In four patients, the system was converted to a different growing-rod construct. There were four nonsurgical complications. Detailed overview of complications is visible in Table 2. No superficial 
Table 4 Height measurements and spinal growth rates (mean $\pm \mathrm{SD}$; range)

\begin{tabular}{|c|c|c|c|c|c|c|}
\hline & $\begin{array}{l}\text { Pre-op }(n=18) \\
(\mathrm{mm})\end{array}$ & $\begin{array}{l}\text { Post-op }(n=18) \\
(\mathrm{mm})\end{array}$ & $\begin{array}{l}\text { Last FU }(n=18) \\
(\mathrm{mm})\end{array}$ & $\begin{array}{l}\text { Length gain rate } \\
\text { post-op to } 1 \text {-year } \\
\text { FU }(n=18)(\mathrm{mm} / \\
\text { year })\end{array}$ & $\begin{array}{l}\text { Length gain rate } \\
\text { post-op to 2-year } \\
\text { FU }(n=18)(\mathrm{mm} / \\
\text { year })\end{array}$ & $\begin{array}{l}\text { Length gain rate } \\
\text { post-op to last FU } \\
(n=18)(\mathrm{mm} / \text { year })\end{array}$ \\
\hline $\mathrm{T} 1-\mathrm{S} 1$ & $\begin{array}{l}313 \pm 39 \\
(270-387)\end{array}$ & $\begin{array}{l}337 \pm 31 \\
(304-392)\end{array}$ & $\begin{array}{l}361 \pm 39 \\
(313-449)\end{array}$ & $\begin{array}{l}13.2 \pm 12.5 \\
(-7.0-30.3)\end{array}$ & $\begin{array}{l}11.2 \pm 9.4 \\
(-6.6-30.3)\end{array}$ & $\begin{array}{l}10.3 \pm 8.5 \\
(-0.3-30.3)\end{array}$ \\
\hline $\mathrm{T} 1-\mathrm{T} 12$ & $\begin{array}{l}196 \pm 22 \\
(165-237)\end{array}$ & $\begin{array}{l}208 \pm 17 \\
(187-242)\end{array}$ & $\begin{array}{l}223 \pm 22 \\
(185-278)\end{array}$ & $\begin{array}{l}9.0 \pm 7.2 \\
(-1.9-21.7)\end{array}$ & $\begin{array}{l}7.5 \pm 5.5 \\
(-1.1-19.3)\end{array}$ & $\begin{array}{l}6.7 \pm 5.4 \\
(-3.6-19.3)\end{array}$ \\
\hline Instrumented & $\begin{array}{l}239 \pm 40 \\
(173-308)\end{array}$ & $\begin{array}{l}259 \pm 39 \\
(189-340)\end{array}$ & $\begin{array}{l}281 \pm 46 \\
(199-364)\end{array}$ & $\begin{array}{l}14.0 \pm 10.7 \\
(-9.0-37.3)\end{array}$ & $\begin{array}{l}9.6 \pm 9.6 \\
(-15.3-29.9)\end{array}$ & $\begin{array}{l}9.1 \pm 6.7 \\
(-0.4-21.4)\end{array}$ \\
\hline \multicolumn{2}{|c|}{ Freehand T1-S1 coronal } & $\begin{array}{l}352 \pm 33 \\
(312-404)\end{array}$ & $\begin{array}{l}375 \pm 41 \\
(320-475)\end{array}$ & $\begin{array}{l}11.1 \pm 15.8 \\
(-20.5-39.4)\end{array}$ & $\begin{array}{l}10.8 \pm 11.5 \\
(-6.9-37.3)\end{array}$ & $\begin{array}{l}10.2 \pm 10.1 \\
(0.2-37.3)\end{array}$ \\
\hline \multicolumn{2}{|c|}{ Freehand T1-S1 sagittal } & $\begin{array}{l}355 \pm 31 \\
(310-405)\end{array}$ & $\begin{array}{l}379 \pm 40 \\
(316-448)\end{array}$ & $\begin{array}{l}12.3 \pm 13.0 \\
(-16.2-31.8)\end{array}$ & $\begin{array}{l}11.0 \pm 8.1 \\
(-1.3-29.1)\end{array}$ & $\begin{array}{l}10.3 \pm 7.5 \\
(-1.3-23.8)\end{array}$ \\
\hline
\end{tabular}

Pre-op radiograph before MCGR implantation, Post-op radiograph before discharge from hospital, $F U$ follow-up

or deep infections or material failures (e.g., screw pull out) were experienced. We did not see obvious PJK $\left(>10^{\circ}\right)$ at the final follow-up. The average implant-related complication rate of our merged data was 0.18 per patient per year. There was a nonsignificant difference between the average weight of patients with and without complication, $34 \mathrm{~kg}$ versus $29 \mathrm{~kg}, p<0.312$ (95\% CI - 5.3-15.6), respectively. During the revision surgery, metallosis was found at the actuator to rod junction. During revision, we did not observe obvious fusions. We did not exchange the MCGR with a new MCGR, the MCGRs that were removed typically failed to distract when removed.

\section{Discussion}

These medium-term follow-up results suggest that a combination of a single concave MCGR and a contralateral passive sliding system with apical control is feasible and safe. The MCGR Hybrid was able to correct and maintain alignment and growth comparable to other MCGR results [15-18]. The observed slight increase of the major curve is a well-known phenomenon that has been observed with all other growthfriendly systems including MCGR, as well [3, 16-18]. This slight loss of correction over time did not mandate revision in any of the patients. Rotation in the apex after surgery did not change significantly over time. The minimal increase in rotation could indicate that this hybrid has apical control, although this assessment on plain $\mathrm{X}$ rays is relatively inaccurate. The mean T1S1 growth rate of $10 \mathrm{~mm} /$ year over 3 years is well acceptable and in accordance to physiological growth $[19,20]$. In general, we have the experience that conversion patients have a stiffer spine. This is not obvious in terms of growth from our results. Growth is better than the $3-4 \mathrm{~mm} /$ year reported in MCGR papers with similar follow-up time $[17,18]$. Sankar et al. investigated length gain achieved with every distraction of TGR [21]. They found that length gains decreased with every additional lengthening over time. More recently, Cheung et al. found similar reduced lengthenings with MCGR [22]. We found higher distraction rates in the first-year results $(13 \mathrm{~mm} /$ year) compared to the distraction rate in the period from 1 year until last follow $(7 \mathrm{~mm} /$ year distraction). This supports our general impression of diminishing returns with the MCGR over time [21, 22]. Whether our protocol of distraction every 3 months up to stalling of the actuator is the most optimal to prevent diminishing returns remains to be determined. Other publications have done this on a monthly basis or semi-annually [21, 22].

The MCGR that were removed typically failed to distract and were send for analysis to the manufacturer. Unfortunately, this did not give more insight in the failure mechanism. The sliding construct did not show failures.

Currently, no publication has reported on spinal balance outcomes after MCGR surgery. Akbarnia et al. investigated balance in a group of the traditional growing-rod EOS patients with a comparable minimum 2-year follow-up time [23]. The coronal balance (deviation from the midline) with growing rods changed from 2.8 to $1.8 \mathrm{~cm}$ and was $2.0 \mathrm{~cm}$ at the latest follow-up or post-final fusion. The sagittal balance in growing rods (C7 plumb line deviation) changed from 3.7 to $2.3 \mathrm{~cm}$ after surgery to $3.9 \mathrm{~cm}$ at last follow-up [23]. If we compare our MCGR results with the traditional growing rods, we find that the coronal balance was comparable and that the sagittal balance in our group did improve $(0.6 \mathrm{~cm})$. While encouraging, our group is too small to conclude a benefit in balance from the hybrid system.

Growth-friendly surgeries have high rates of both planned and unplanned surgeries because of surgical lengthening's and complications, respectively [4]. MCGR has reduced planned re-operations by shifting from surgical to nonsurgical lengthening. However, unplanned surgeries because of complications do occur. MCGR studies with a minimum 2-year follow-up report that patients requiring unplanned 


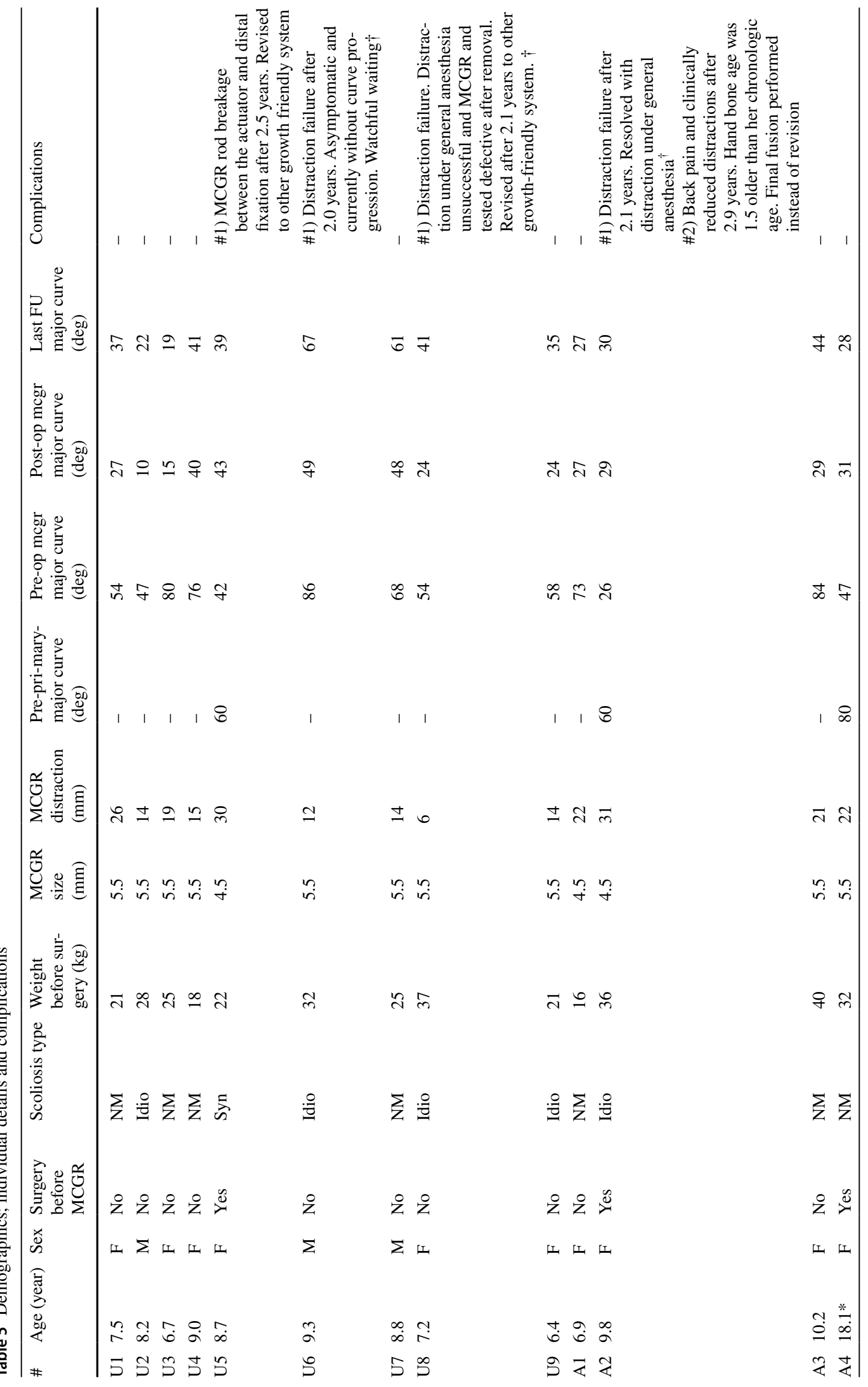




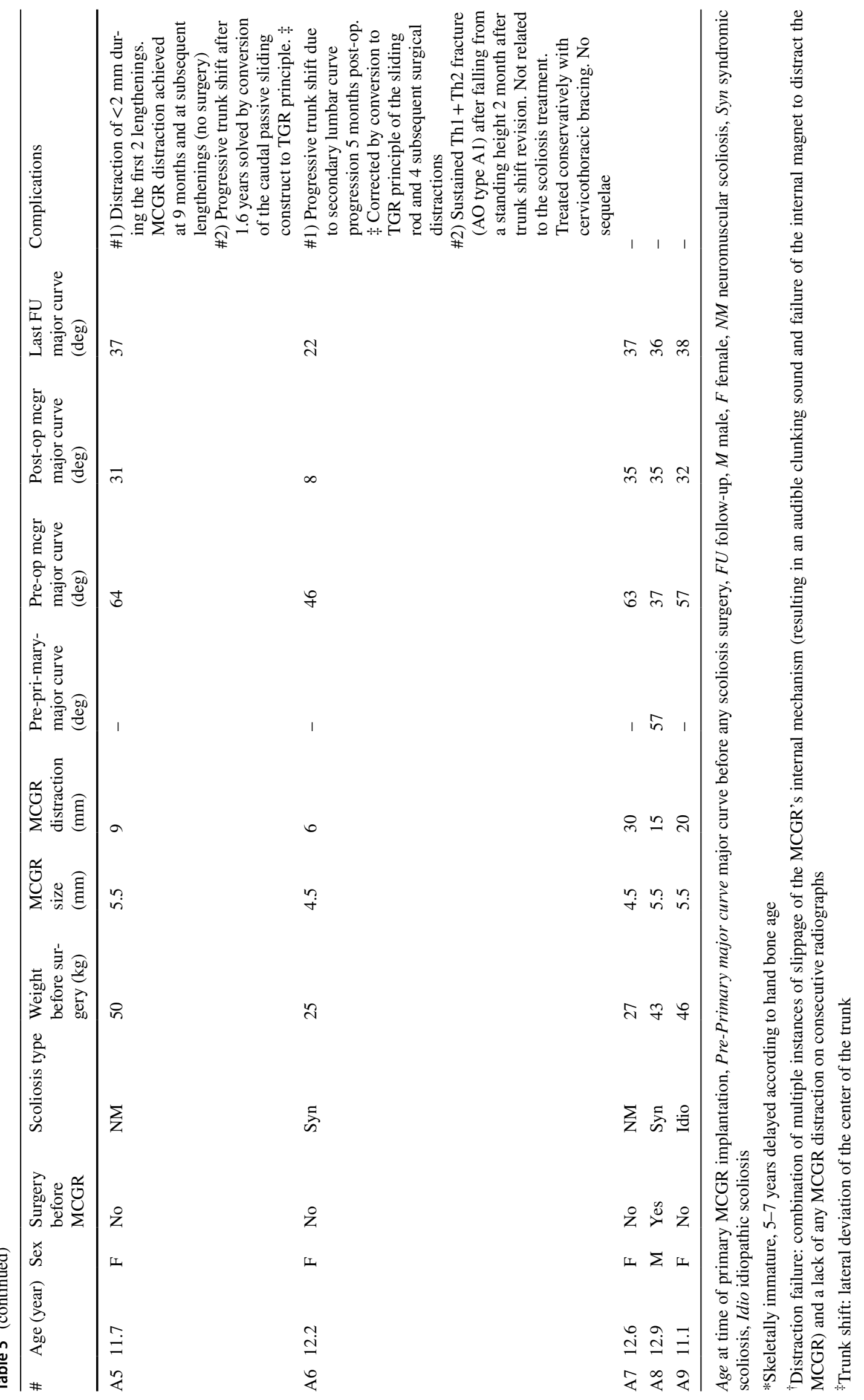


surgery ranged from 39 to $75 \% .92$ patients combined from four studies experienced 17 cases of a nonfunctioning MCGR and 12 cases of rod fracture requiring unplanned surgery (a total of 31\%) [15, 16, 24, 25]. Our cohort consisting of 18 patients experienced two cases of a non-distracting MCGR after implantation and one rod fracture requiring unplanned reoperation (a total of 17\%). The implant-related complications (including complications not requiring unplanned surgery, e.g., temporary distraction failures or painful distractions) ranged from 48 to $75 \%$ in studies with a minimum 2-year follow-up [16, 24, 25]. One study reported a complication rate of 0.23 per patient per year [25]. Our results show a comparable or lower complication rate of 0.18 per patient per year. We found that the average time until conversion (from MCGR hybrid to other growth-friendly systems) was 1.7 years. In one patient, this reoperation was at 6 months because of a progressive trunk shift due to too high distal level of instrumentation. Whether one slidingrod configuration should be preferred cannot be determined based on the limited data and different patient groups. Some complications were due to failure of rod distraction and it has been suggested that this is possibly due to increased body habitus (weight, height, and BMI) and increased distance between external magnet and MCGR actuator in some patients. Although our patient group is too small to draw conclusions, we did not see an obvious relation between body weight and failure. However, we did not correct for BMI.

Several studies have been published regarding cost estimates of MCGR treatment in different health care systems. The general conclusion is that the reduced number of surgeries outweighs the high initial implant cost $[5,7,15,16]$. The results of our study, with a hybrid construct using only one MCGR, indicate performance in terms of efficacy and safety that are at least on par with dual MCGRs. Although the installation of the sliding rod on the contralateral side is a bit more challenging than an MCGR, these extra 10-20 min are probably cost-effective as the cost of the implants is reduced by about 9.000 USD. These results are far from ideal, but are currently the most optimal of all documented growthfriendly techniques. Whether the additional apical control is another advantage for 3D correction and biomechanical stability is yet to be examined.

\section{Limitations}

The current results are at interim. Since more complications were experienced in patients with longer follow-up time, more complications are to be expected until final fusion or end of growth. Systematic errors in radiographic measurements is a potential bias (e.g., using the wrong levels in T1-S1 height). Therefore, all the outcomes were measured on five time points (postoperatively, 6 months, 1 year,
2 years, and latest follow-up) and cross-audited by two observers for discrepancies. The standard T1-S1 height measurement can increase by a reduction in major curve or kyphosis over time. To reduce this problem, we added T1-S1 freehand measurements in both coronal and sagittal planes. We included patients from two spine centers and included cases with the previous growth rod instrumentation systems who were switched to the MCGR hybrid which might be confounding the outcome of this study. However, nothing indicates that these factors (positively) influenced our results, although there may be a bias towards only inclusion of patients with an obvious dominant curve that could be treated with this strategy. We found out that for Lenke 3 or other obvious double curve configuration, this technique is probably not a good strategy. On the other hand, the patients were relatively old and some were conversion cases. In hindsight, it is arguable if the MCGR was really worth the high complication rate of this treatment for some of the patients. We believe that an age between 8 and 10 years and failed bracing is the ideal indication.

\section{Conclusions}

This is the first report on medium-term results of a hybrid concept that consists of a single MCGR for concave distraction combined with a contralateral passive gliding rod construct with apical control. The 3D correction is good and spinal growth is preserved. The complication rate is fairly low, which suggests a cost-effectiveness as compared to dual MCGR treatment.

\section{Key points}

- This study reported the medium-term results of 18 EOS patients treated with an MCGR hybrid of a single concave MCGR combined with a convex sliding rod with a minimum follow-up of 2 years.

- The MCGR hybrid is safe and effective in the treatment of EOS.

- The complication rate is fairly low and only uses one MCGR rod which suggests a cost-effectiveness as compared to dual MCGR treatment.

Funding No funding was received for this work. 


\section{Compliance with ethical standards}

Conflict of interest All authors declare that they have no commercial associations that might pose a conflict of interest in relation to the submitted manuscript.

Open Access This article is licensed under a Creative Commons Attribution 4.0 International License, which permits use, sharing, adaptation, distribution and reproduction in any medium or format, as long as you give appropriate credit to the original author(s) and the source, provide a link to the Creative Commons licence, and indicate if changes were made. The images or other third party material in this article are included in the article's Creative Commons licence, unless indicated otherwise in a credit line to the material. If material is not included in the article's Creative Commons licence and your intended use is not permitted by statutory regulation or exceeds the permitted use, you will need to obtain permission directly from the copyright holder. To view a copy of this licence, visit http://creativecommons.org/licenses/by/4.0/.

\section{References}

1. Branthwaite MA (1986) Cardiorespiratory consequences of unfused idiopathic scoliosis. Br J Dis Chest 80:360-369

2. Davies G, Reid L (1971) Effect of scoliosis on growth of alveoli and pulmonary arteries and on right ventricle. Arch Dis Child $46: 623$

3. Luhmann SJ, McCarthy RE (2017) A comparison of SHILLA GROWTH GUIDANCE SYSTEM and growing rods in the treatment of spinal deformity in children less than 10 years of age. J Pediatr Orthoped 37:E567-E574

4. Bess S, Akbarnia BA, Thompson GH et al (2010) Complications of growing-rod treatment for early-onset scoliosis analysis of one hundred and forty patients. J Bone Joint Surg 92:2533-2543

5. Cheung KMC, Cheung JPY, Samartzis D et al (2012) Magnetically controlled growing rods for severe spinal curvature in young children: a prospective case series. Lancet 379:1967-1974

6. Skov ST, Wijdicks SPJ, Bunger C et al (2018) Treatment of earlyonset scoliosis with a hybrid of a concave magnetic driver (magnetic controlled growth rod) and a contralateral passive sliding rod construct with apical control: preliminary report on 17 cases. Spine J 18:122-129

7. Thakar C, Kieser DC, Mardare M et al (2018) Systematic review of the complications associated with magnetically controlled growing rods for the treatment of early onset scoliosis. Eur Spine J 27:2062-2071

8. Thompson GH, Akbarnia BA, Kostial P et al (2005) Comparison of single and dual growing rod techniques followed through definitive surgery: a preliminary study. Spine 30:2039-2044

9. Polly DW, Ackerman SJ, Schneider K et al (2016) Cost analysis of magnetically controlled growing rods compared with traditional growing rods for early-onset scoliosis in the US: an integrated health care delivery system perspective. Clinicoecon Outcomes Res 8:457-465

10. Wong CKH, Cheung JPY, Cheung PWH et al (2017) Traditional growing rod versus magnetically controlled growing rod for treatment of early onset scoliosis: cost analysis from implantation till skeletal maturity. J Orthop Surg-Hong. https://doi. org/10.1177/2309499017705022

11. Charroin C, Abelin-Genevois K, Cunin V et al (2014) Direct costs associated with the management of progressive early onset scoliosis: estimations based on gold standard technique or with magnetically controlled growing rods. Orthop Traumatol Surg Res 100:469-474

12. von Elm E, Altman DG, Egger M et al (2008) The Strengthening the Reporting of Observational Studies in Epidemiology [STROBE] statement: guidelines for reporting observational studies. Gac Sanit 22:144-150

13. Nuvasive (2018) MAGEC noninvasive growth modulation. Accessed 02 Nov 2018

14. Nash CL, Moe JH (1969) A study of vertebral rotation. J Bone Joint Surg 51:223

15. Kwan KYH, Alanay A, Yazici M et al (2017) Unplanned reoperations in magnetically controlled growing rod surgery for early onset scoliosis with a minimum of two-year follow-up. Spine 42:E1410-E1414

16. Hosseini P, Pawelek J, Mundis GM et al (2016) Magnetically controlled growing rods for early-onset scoliosis: a multicenter study of 23 cases with minimum 2 years follow-up. Spine 41:1456-1462

17. Lebon J, Batailler C, Wargny M et al (2017) Magnetically controlled growing rod in early onset scoliosis: a 30-case multicenter study. Eur Spine J 26:1567-1576

18. Keskinen H, Helenius I, Nnadi C et al (2016) Preliminary comparison of primary and conversion surgery with magnetically controlled growing rods in children with early onset scoliosis. Eur Spine J 25:3294-3300

19. Canavese F, Dimeglio A (2013) Normal and abnormal spine and thoracic cage development. World J Orthop 4:167-174

20. Wijdicks SP, Tromp IN, Yazici M, Kempen DH, Castelein RM, Kruyt MC (2018) A comparison of growth among growth friendly systems for scoliosis: a systematic review. Spine J 19(5):789-799

21. Sankar WN, Skaggs DL, Yazici M et al (2011) Lengthening of dual growing rods and the law of diminishing returns. Spine 36:806-809

22. Cheung JPY, Yiu KKL, Samartzis D et al (2018) Rod lengthening with the magnetically controlled growing rod: factors influencing rod slippage and reduced gains during distractions. Spine 43:399-405

23. Akbarnia BA, Marks DS, Boachie-Adjei O et al (2005) Dual growing rod technique for the treatment of progressive early-onset scoliosis: a multicenter study. Spine 30:46-57

24. Teoh KH, Winson DM, James SH et al (2016) Magnetic controlled growing rods for early-onset scoliosis: a 4-year follow-up. Spine J 16:S34-S39

25. Subramanian T, Ahmad A, Mardare DM et al (2018) A six-year observational study of 31 children with early-onset scoliosis treated using magnetically controlled growing rods with a minimum follow-up of two years. Bone Joint J 100:1187-1200

Publisher's Note Springer Nature remains neutral with regard to jurisdictional claims in published maps and institutional affiliations. 